\title{
Eco-friendly synthesis, characterization, in vitro and in vivo anti-inflammatory activity of silver nanoparticle-mediated Selaginella myosurus aqueous extract
}

This article was published in the following Dove Press journal:

International Journal of Nanomedicine

\author{
Philippe Belle Ebanda Kedi ${ }^{1,2}$ \\ Francois Eya'ane Meva ${ }^{3}$ \\ Lebogang Kotsedi ${ }^{2,4,5}$ \\ Edwige Laure Nguemfo 6 \\ Calvin Bogning Zangueu' \\ Agnes Antoinette Ntoumba' \\ Hamza Elsayed Ahmed \\ Mohamed 2,4 \\ Alain Bertrand Dongmo' \\ Malik Maaza ${ }^{2,4}$ \\ 'Department of Animal Biology and \\ Physiology, Faculty of Science, University of \\ Douala, Douala, Cameroon; ${ }^{2}$ Nanosciences \\ African Network (NANOAFNET), iThemba \\ LABS-National Research Foundation, \\ Somerset, South Africa; ${ }^{3}$ Department \\ of Pharmaceutical Sciences, Faculty of \\ Medicine and Pharmaceutical Sciences, \\ University of Douala, Douala, Cameroon; \\ ${ }^{4}$ UNESCO-UNISA Africa Chair in \\ Nanosciences-Nanotechnology, College \\ of Graduate Studies, University of South \\ Africa, Pretoria, South Africa; ${ }^{5}$ Department \\ of Physics, University of the Western \\ Cape, Bellville, Cape Town, South Africa; \\ ${ }^{6}$ Department of Biological Sciences, Faculty \\ of Medicine and Pharmaceutical Sciences, \\ University of Douala, Douala, Cameroon
}

Correspondence: Francois Eya'ane Meva Department of Pharmaceutical Sciences, Faculty of Medicine and Pharmaceutical Sciences, University of Douala, PO Box 270I,

Douala, Cameroon

Tel +237673702913

Email mevae@daad-alumni.de

Alain Bertrand Dongmo

Department of Animal Biology and Physiology,

Faculty of Science, University of Douala,

PO Box 24157, Douala, Cameroon

Tel +23767 6491950

Email alainberd@yahoo.fr
Introduction: There is emerging interest in medicinal plants in the biomedical field, due to their multitude of chemicals which show anti-inflammatory, antimicrobial, antiviral, or antitumoral potential. Research on medicinal plants has shown that nanotechnology could offer new solutions in the quality control, delivery aspects, or in sustaining herbal biological activities. This work reports on the preparation and characterization of silver nanoparticle-mediated Selaginella myosurus plant extract.

Methods: Ultraviolet-visible spectroscopy, Fourier transform infrared spectroscopy, powder $\mathrm{X}$-ray diffraction, energy dispersive X-ray spectroscopy, high-resolution scanning electron microscopy, high-resolution transmission electron microscopy, and selected area electron diffraction have been used to characterize the prepared silver nanoparticles. The synthetic stability was studied by varying concentrations and $\mathrm{pH}$ of reactants. Egg albumin denaturation and carrageenan-induced rat paw edema model were used to ascertain the anti-inflammation.

Results: Ultraviolet-visible spectroscopy gave plasmon resonance ranging between 420 and $480 \mathrm{~nm}$ while Fourier transform infrared spectroscopy proved nano interface functionalized with organics. The powder X-ray diffraction pattern is in agreement with silver and silver chloride nanoparticles of crystallite size $33.7 \mathrm{~nm}$ and $44.2 \mathrm{~nm}$ for silver and silver chloride, respectively. Energy dispersive $\mathrm{X}$-ray spectroscopy enables elemental characterization of the particles consisting of silver and silver chloride among main elements. Spherical silver grain of $58.81 \mathrm{~nm}$ average size has been depicted with high-resolution scanning electron microscopy and high-resolution transmission electron microscopy. Inhibitions of $99 \%$ and $60 \%$ were obtained in vitro and in vivo, respectively.

Conclusion: The albumin denaturation and carrageenan-induced rat hind paw edema model to assess the anti-inflammatory potential of generated nanoparticles suggests that the silver nanoparticles may act as reducing/inhibiting agents on the release of acute inflammatory mediators. Hence, this work clearly demonstrated that silver nanoparticles mediated-Selaginella myosurus could be considered as a potential source for anti-inflammatory drugs.

Keywords: eco-friendly synthesis, silver nanoparticles, Selaginella myosurus, anti-inflammatory

\section{Introduction}

Inflammation is a physical response that protects against injury, infection, and stress through multiple mechanisms. It is well-known that the oxidative stress that occurs in the inflammatory response can facilitate tumor progression, increase the risk of atherosclerosis, cause coronary heart disease, cause lesions of Alzheimer's disease, and promote insulin resistance and diabetes. ${ }^{1-3}$ In such diseases, inflammation is a primary cause, and 
therefore, treatment of the inflammatory condition may be an effective therapeutic approach. Most clinically, important medicines belong to steroidal or nonsteroidal anti-inflammatory chemical. Although these have potent activity, the long-term administration is required for the treatment of chronic diseases. ${ }^{4}$ Furthermore, these drugs have various and severe adverse effects that have compelled the need for identification of alternative substances that can resolve inflammation in a way that is homeostatic, modulatory, efficient, and well tolerated by the body. ${ }^{5}$ One such alternative is the use of medicinal plants because their therapeutic value has been well established for various human diseases. It is well documented that therapeutic effects of herbal medicine are due to active components present in their extract. ${ }^{6}$ However, most of these active components possess insoluble character leading to lower bioavailability, increased systemic clearance, ${ }^{7}$ and required unnecessarily high systemic administration. ${ }^{8}$ Applying nanotechnology to herbal drugs may lead to the development of nano herbal products, which will open a new era of herbal discovery because nanosized drug delivery systems have many advantages to offer including solubility, bioavailability, pharmacological activity enhancement, protection from toxicity, sustained delivery, and protection from physical and chemical degradation. ${ }^{9}$

Nanotechnology deals with the synthesis and fabrication of materials at the nanoscale level (1-100 nm). It is the critical length scale at which certain novel size-related properties develop and the material starts behaving differently than the molecules or bulk material. ${ }^{10}$ At this scale, materials exhibit some unexpected and unusual new properties that cannot be defined by the classical laws of physics. ${ }^{11}$ It is these unusual properties that have attracted the immense attention of researchers from almost every science field including biology and medicine. ${ }^{10}$ Among all available nanoparticles, silver nanoparticles are the most important because in low concentrations they are not toxic to human health ${ }^{12}$ and exhibited anti-inflammatory, ${ }^{5}$ antiviral, ${ }^{13}$ and antibacterial ${ }^{14}$ activities, thereby being an excellent choice for multiple roles in the medical field. The literature describes various methods to synthesize silver nanoparticles including physical and chemical engineering, but the use of biological systems (plants and microbes) as potential nanofactories is gaining more importance as they are not expensive, not cumbersome, and respectful for the environment. ${ }^{10}$

Selaginella myosurus is a terrestrial, perennial, and herbaceous plant that grows in shallow soils on rocky outcrops of slopes of small hills in direct sunlight in humid tropical regions. ${ }^{15}$ Leaves of $0.5-1 \mathrm{~cm}$ long resembling scales are spirally arranged on a creeping stem. ${ }^{16}$ Known as tunda, the plant is used by Douala community for the traditional feast, burial ceremonies, and to invoke ancestral spirits (personal communication). In pharmacopeia, it is utilized to cure postpartum hemorrhage, menstrual disorder, respiratory and urinary tract infections, skin disease, cardiovascular problems, cancer, headache, fever, rheumatism, bone fracture, diabetes, hepatitis, wounds, and to improve fitness and endurance of the body. ${ }^{17-19}$ Extracts and isolated compounds of some species have shown great pharmacological activities such as antinociceptive, ${ }^{20}$ antiinflammatory, ${ }^{21}$ antimutagenic, ${ }^{22}$ antispasmodic, ${ }^{23}$ cytotoxic, immunostimulant, and RNA reverse transcriptase inhibitory agents. ${ }^{24}$ In our previous study, we demonstrated the antiinflammatory potential of $S$. myosurus aqueous extract. ${ }^{25}$ The present work was undertaken to synthesize, characterize, and evaluate the anti-inflammatory activity in both in vitro and in vivo systems of silver nanoparticle-mediated $S$. myosurus aqueous extract. Thereby, the potential advantages of phytomedicine and nanomedicine can be combined to result in a more enhanced and synergistic anti-inflammatory effect.

\section{Materials and methods Plant collection and preparation of the extract}

The whole plant of $S$. myosurus (Figure 1) was collected at Dibombari (N04 11.585'; E009 39.958'), Littoral region, Cameroon, in April 2014 and authenticated by Dr Tchiengue Barthelemy at the National Herbarium, Yaounde, in comparison with a voucher specimen previously deposited (no 18192/ $\mathrm{SFR} / \mathrm{Cam}$ ). The entire freshly collected plant was thoroughly washed with running tap water followed by distilled water to remove all surface contaminants and finely cut. Ten grams of the plant was introduced into a conical flask containing $100 \mathrm{~mL}$ preheated distilled water $\left(80^{\circ} \mathrm{C}\right)$ and stirred for 5 minutes using a hot plate equipped with a magnetic stirrer. After cooling at room temperature, the solution was filtered using Whatman paper no 1 and used as $S$. myosurus aqueous

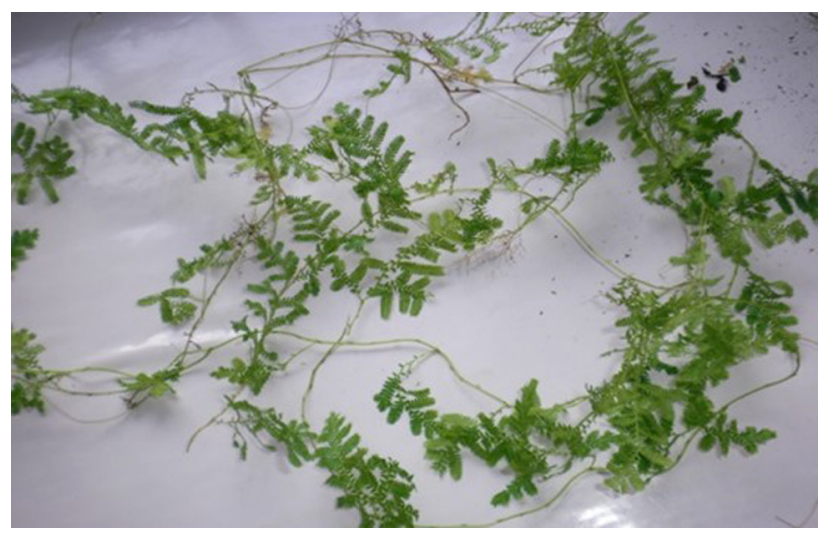

Figure I Selaginella myosurus plant. 
extract throughout, being used for 1 week due to gradual loss of plant extract viability for prolonged storage. Ten milliliters of the freshly prepared aqueous extract was introduced into a Petri dish and left overnight in the oven at $45^{\circ} \mathrm{C}$. After complete drying, the extract was weighted and the amount of plant extract present in the solution was calculated.

\section{Biological synthesis of silver nanoparticles}

Silver nanoparticles were synthesized according to a wellknown procedure with slight modifications. ${ }^{26}$ Ten milliliters of freshly prepared aqueous extract was added to $50 \mathrm{~mL}$ silver nitrate aqueous solution $(1 \mathrm{mM})$ for the bioreduction process. The mixture was incubated at room temperature in the dark to minimize the photoactivation of silver nitrate under static conditions until changing color appearance. The color change involved the formation of silver nanoparticles. The mixture was then centrifuged (D-7200; Hettich, Tuttlingen, Germany) at 6,000 rpm for 20 minutes and washed twice with distilled water and once with ethanol 95\%. Purified pellets were kept into a Petri dish, dried in the oven at $60^{\circ} \mathrm{C}$ for 24 hours, and used for characterization and anti-inflammatory studies.

\section{Stability studies of S. myosurus silver nanoparticles}

The optimum synthesis and stability of silver nanoparticles were investigated by varying $\mathrm{pH}$ gradients $2,4,6,8,10$, and 12 , extract quantities $2,4,6,8$, and $10 \mathrm{~mL}$ corresponding to 1.2 , 2.4, 3.6, 4.8, and $6 \mathrm{mg}$ and silver nitrate concentrations $(1,2,3$, 4 , and $5 \mathrm{mM}$ ) of the previous reaction mixture. ${ }^{27}$ Two milliliter aliquots of different samples were taken, and absorbance was measured at 5 minutes, 1 hour, 3 hours, 24 hours, 48 hours, 72 hours, and 192 hours after the beginning of the reaction. The $\mathrm{pH}$ was adjusted using $0.1 \mathrm{~N} \mathrm{H}_{2} \mathrm{SO}_{4}$ and $0.1 \mathrm{~N} \mathrm{NaOH}$ solutions.

\section{Characterization of silver nanoparticles} Ultraviolet (UV)-visible spectroscopic measurement

The reduction of silver ions was monitored by measuring UV-visible spectrum of the reaction mixture at 5 minutes, 1 hour, 3 hours, 24 hours, 48 hours, 72 hours, and 192 hours using the UV-visible spectrophotometer (UV-line 9,100 single beam, halogen light source, $1 \mathrm{~nm}$ resolution). Distilled water was used as a blank.

\section{Fourier transform infrared (FTIR) spectroscopy}

FTIR spectrum was recorded at room temperature through potassium bromide pellet method. Samples were grinded with $\mathrm{KBr}$ pellets and kept in infrared path, and the spectrum was measured using a Nicolet IS5 model of Thermo Scientific operating at a resolution of $0.4 \mathrm{~cm}^{-1}$.

\section{Powder X-ray spectroscopy (PXRD)}

The PXRD spectroscopy measurements of purified silver nanoparticles were carried out using a Panalytical Empyrean Serie 2 X-ray diffractometer (Cu K-Alpha1 [A] 1.54060,

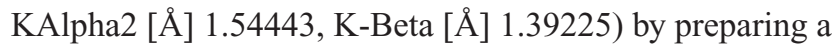
thin film on silicon substrate.

High-resolution scanning electron microscopy (HR-SEM) and energy dispersive X-ray spectroscopy (EDS)

The biosynthesized silver nanoparticles were subjected to HR-SEM for morphology determination. A small amount of sample powder was deposited on a carbon-coated carbon grid and coated with carbon using a coating sputter coater (Quorum Q 150 TES) to increase the conductivity of the sample. SEM images were taken using Carl Zeiss Auriga Field Emission Scanning Electron microscope image at $5 \mathrm{keV}$. EDS spectrum for elemental analyses was collected with an Oxford Instruments X-Max solid-state silicon drift detector operating at $20 \mathrm{keV}$ coupled to a TECNAI G2 HR-SEM.

High resolution-transmission electron microscopy (HR-TEM) and selected area electron diffraction (SAED)

For the HR-TEM, the sample was prepared by placing a drop of the nanoparticle suspension on the carbon-coated copper grid and allowing water evaporation inside the vacuum dryer. HR-TEM observations as well as SAED were carried out using an FEI Tecnai G2 Field Emission Gun - HR-TEM operating at $200 \mathrm{kV}$.

\section{Evaluation of anti-inflammatory activities}

Animals and ethics

Wistar albinos rats of 8 weeks old, weighing 130-150 g, housed in standard polypropylene cage at room temperature $\left(24^{\circ} \mathrm{C} \pm 2^{\circ} \mathrm{C}\right)$ and relative humidity under light and dark cycle (from 6 am to $6 \mathrm{pm}$ ) were used for this study. They were obtained from the Laboratory of Animal Biology, Faculty of Science, University of Douala. They were fed with standard pellet food and tap water ad libitum during 1 week of acclimatization. All experiments were carried out according to the approved protocol by the Institutional Ethical Committee of the University of Douala (Protocol approval number CEIUDo/809/02/2017/T).

\section{Inhibition of albumin denaturation assay}

A reaction mixture $(5 \mathrm{~mL})$ consisting of $0.2 \mathrm{~mL}$ of egg albumin (from fresh hen's egg), $2.8 \mathrm{~mL}$ of PBS ( $\mathrm{pH} 6.4$ ), and $2 \mathrm{~mL}$ of varying concentrations of silver nanoparticles 
$(25,50,100,200$, and $400 \mu \mathrm{g} / \mathrm{mL})$ was incubated at $37^{\circ} \mathrm{C}$ in a biochemical oxygen demand incubator for 15 minutes and then heated at $70^{\circ} \mathrm{C}$ for 5 minutes. A similar volume of distilled water served as control. After cooling, their absorbance was measured at $660 \mathrm{~nm}$ by using the vehicle as blank. Acetylsalicylic acid at concentrations of 5, 10, 15, 25, 50 , and $100 \mathrm{mg} / \mathrm{mL}$ was used as reference drug and treated similarly for determination of absorbance. ${ }^{28,29}$ The percentage of inhibition of protein denaturation was calculated by using Equation 1:

$$
\% \text { inhibition }=100 \times \frac{\mathrm{Vt}}{\mathrm{Vc}-1}
$$

where $\mathrm{Vt}$ is the absorbance of the test sample and $\mathrm{Vc}$ is the absorbance of control. The drug concentration for $50 \%$ inhibition was determined from the dose-response curve by plotting percentage inhibition with respect to control against treatment concentration.

\section{Carrageenan-induced rat paw edema method}

The anti-inflammatory activity of silver nanoparticles was evaluated on a carrageenan-induced rat paw edema model as described by Winter et al. ${ }^{30}$ The experimental animals were randomly divided into five groups $(n=6)$. Group I served as a control receiving inflammatory inducing agent only. Group II served as standard, and groups III, IV, and V served as test. Acute inflammation was induced by a single subplantar injection of $0.1 \mathrm{~mL}$ of carrageenan ( $1 \%$ carrageenan suspended in $0.9 \% \mathrm{NaCl}$ ) in the right hind paw of the rats 1 hour following administration (per os) of silver nanoparticles at doses of 100 , 200 , and $400 \mu \mathrm{g} / \mathrm{kg}$ for test groups, indomethacin $(10 \mathrm{mg} /$ $\mathrm{kg}$ ) for standard group, or distilled water $(10 \mathrm{~mL} / \mathrm{kg})$ for control group. Paw size was measured by means of volume displacement technique using water plethysmometer (No 37140; Ugo Basile, Cologne, Italy) immediately before and 30 minutes, 1 hour, 2 hours, 3 hours, 4 hours, and 5 hours after the carrageenan injection. The edema was expressed as the increase in paw volume, and the percentage of inhibition of edema was expressed as the reduction in volume with respect to the control group using Equation 2:

$$
\mathrm{I} \%=\frac{\left(\mathrm{V}_{\mathrm{t}}-\mathrm{V}_{0}\right)_{\text {control }}-\left(\mathrm{V}_{\mathrm{t}}-\mathrm{V}_{0}\right)_{\text {treated }}}{\left(\mathrm{V}_{\mathrm{t}}-\mathrm{V}_{0}\right)_{\text {control }}} \times 100
$$

where $\mathrm{V}_{\mathrm{t}}$ is the average volume for each group and $\mathrm{V}_{0}$ is the average volume obtained for each group before any treatment. $^{31}$

\section{Statistical analysis}

Results are expressed as mean \pm SEM. The difference between treated groups and control group was compared using one-way ANOVA followed by Dunnett's post hoc test. The analyses were carried out using software PRISMA (version 5.01; GraphPad Software, Inc., San Diego, CA, USA). $P$-values $<0.05$ were considered significant.

\section{Results \\ Visual observations of biosynthesized nanoparticles}

Silver nanoparticles were biosynthesized using S. myosurus aqueous extract. The formation of silver nanoparticles was preliminarily observed by the change in the silver nitrate solution color to brownish yellow while adding the aqueous extract as depicted in Figure 2. The brownish yellow color is due to the excitation of free electrons in the nanoparticles and occurs in 3 hours at room temperature. After 24 hours, no further color change was observed due to stabilization of the synthesized nanoparticles.

\section{Effects of condition reaction on the biosynthesis of nanoparticles \\ Effect of $\mathrm{pH}$}

The UV-visible spectra absorption bands of synthesized silver nanoparticles using $S$. myosurus at different $\mathrm{pH}$ are

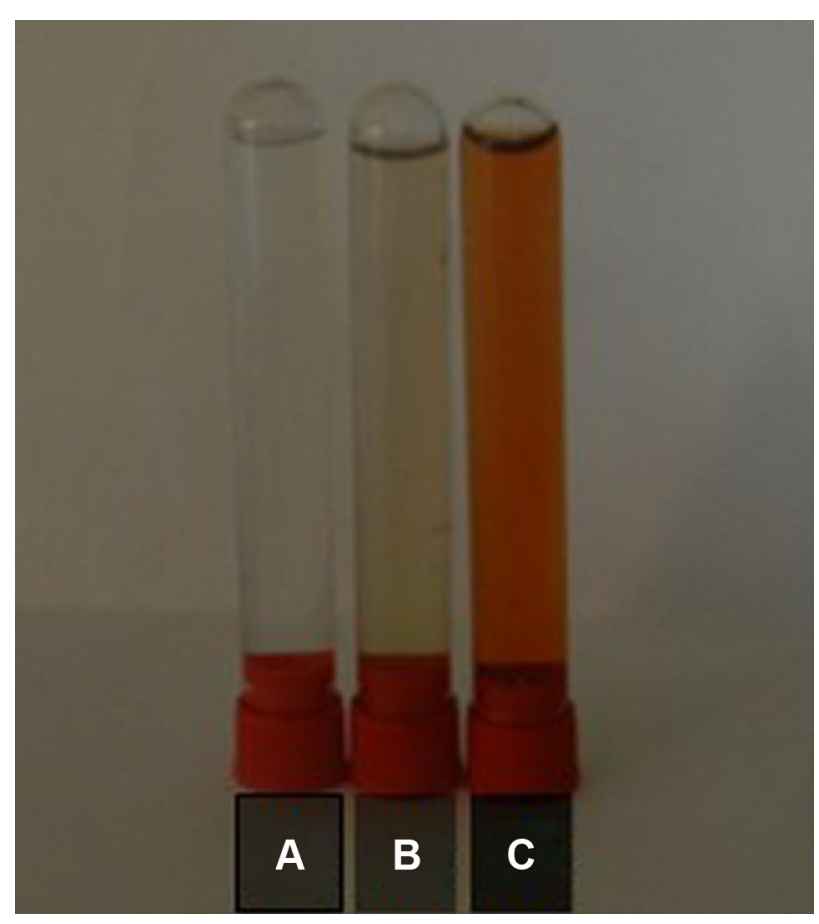

Figure 2 Silver nitrate (A), plant extract (B), and silver nanoparticles (C) solutions. 
shown in Figure 3. It can be seen that nanoparticles are well synthesized at basic $\mathrm{pH}$ with an optimal $\mathrm{pH} 12$. The plasmon absorbance bands increase with increasing $\mathrm{pH}$ from 8 to 12 and decrease with decreasing $\mathrm{pH}$ from 6 to 2 . Furthermore, the yellowish nanoparticles color ( $\mathrm{pH} 6$ ) tends change to brown ( $\mathrm{pH}$ 12) with increasing $\mathrm{pH}$, whereas no change in color or absorbance has been recorded in the acid middle.

\section{Influence of extract quantity}

Figure 4A and B shows the color appearance and evolution of surface plasmon, respectively, in the synthesis of silver nanoparticles using 2, 4, 6, 8, and $10 \mathrm{~mL}$ aqueous extract. Results were recorded 24 hours following incubation time, and it is notable that the production of nanoparticles increases with increasing extract quantity.

\section{Silver nitrate concentration impact}

Different silver nitrate solutions of different concentrations were utilized for the synthesis of nanoparticles. The color change and the surface plasmon absorbance band evolution using 1, 2, 3, 4, and $5 \mathrm{mM}$ silver nitrate solutions are shown in Figure 5A and B, respectively. As is clearly seen, the synthesis of nanoparticles increased with increasing silver nitrate concentration. Visible spectra were recorded 24 hours following incubation time.

\section{Characterization of biosynthesized nanoparticles \\ UV-visible spectral studies}

UV-visible spectroscopy was used to detect and confirm the presence of nanoparticles in the sample based on their optical absorbance peaks. The absorption spectra of the synthesized

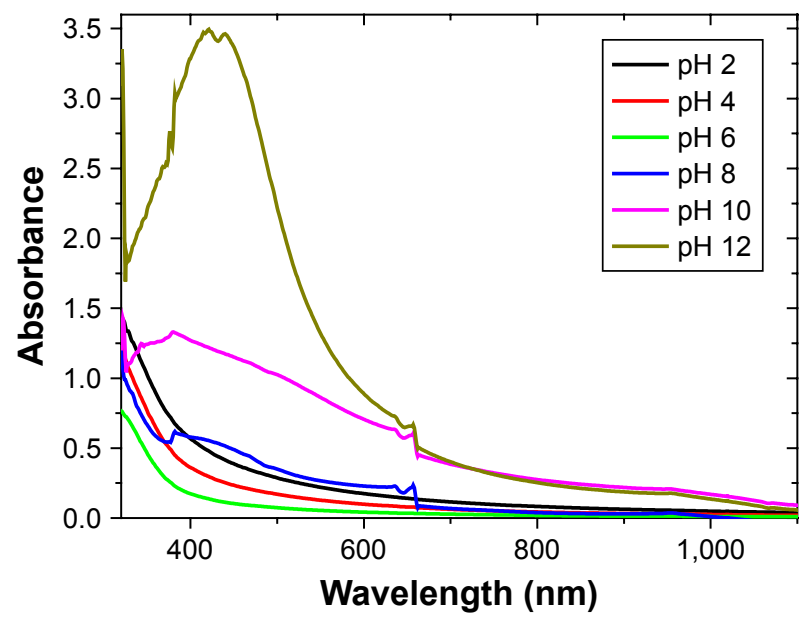

Figure 3 Ultraviolet-visible spectra of the variation of $\mathrm{pH}$.
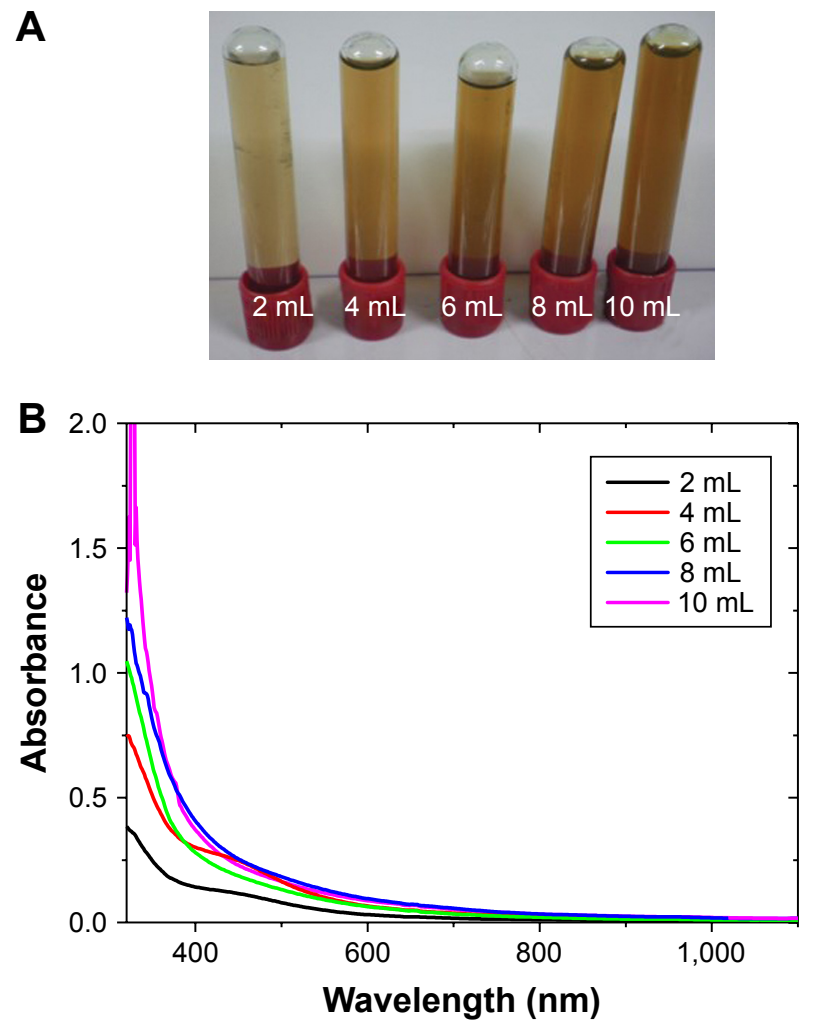

Figure 4 (A) Color of silver nanoparticle solution at different extract quantities. (B) Ultraviolet-visible spectra of the variation of extract quantities.

silver nanoparticles were recorded against water in order to monitor their formation and their stability. Figure 6 depicts the UV-visible spectra of synthesized silver nanoparticles using $50 \mathrm{~mL}$ of $\mathrm{AgNO}_{3} 10^{-3} \mathrm{~mol} / \mathrm{L}$ with $10 \mathrm{~mL}$ of plant extract as a function of time. The characteristic peak of silver nanoparticle known as the surface plasmon resonance timely increased and is in the range $420-480 \mathrm{~nm}$.

\section{FTIR spectroscopy results}

The FTIR spectrum to determine the various functional groups which acted as capping agents is depicted in Figure 7. The vibrational band in the $3,030 \mathrm{~cm}^{-1}$ region is associated with the stretching modes of $\mathrm{C}-\mathrm{H}, \mathrm{N}-\mathrm{H}$, and $\mathrm{O}-\mathrm{H}$ bonds. Absorption bands at 2,920 and 2,839 $\mathrm{cm}^{-1}$ are due to stretching vibrations of $\mathrm{C}-\mathrm{H}$ group. The absorptions occurring at $2,300-2,400 \mathrm{~cm}^{-1}$ can be attributed to $\mathrm{O}=\mathrm{C}=\mathrm{O}$ molecules. The band at 1,606 is attributed to the bending vibration modes of the aromatic ring $\mathrm{C}=\mathrm{C}$ and $\mathrm{N}-\mathrm{H}$ bond of amines. The absorption band at $1,323 \mathrm{~cm}^{-1}$ is due to the presence of the $\mathrm{C}-\mathrm{N}$-like amine groups. The band at 1,483 represents aliphatic $\mathrm{C}-\mathrm{H}$ vibrations. The weak band at 1,169 is $\mathrm{C}-\mathrm{O}-$ stretch. The peak centered at $1,015 \mathrm{~cm}^{-1}$ is the indication of $\mathrm{C}-\mathrm{H}$ in-plane/C-H out-of-plane deformation. The bonds in the area $670-1,000 \mathrm{~cm}^{-1}$ correspond to stretching vibrational 
A
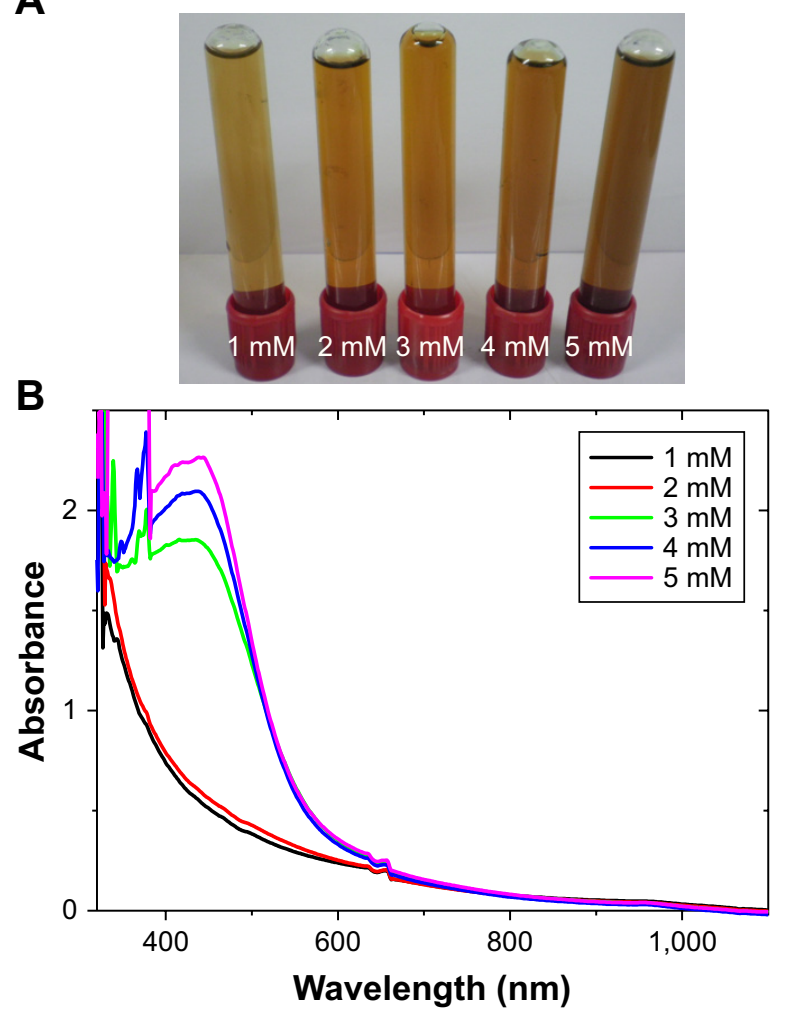

Figure 5 (A) Color of silver nanoparticle solution at different silver nitrate concentrations. (B) Ultraviolet-visible spectra of the variation of silver nitrate concentration.

band of $=\mathrm{C}-\mathrm{H}$. The two bands at $759 \mathrm{~cm}^{-1}$ and $685 \mathrm{~cm}^{-1}$ are due to the out-of-plane bending vibrations of $\mathrm{C}-\mathrm{H}$ groups.

\section{PXRD results}

X-ray diffraction was used for the characterization of the crystal structure of the silver nanoparticles. PXRD pattern of the synthesized silver nanoparticles shown in Figure 8

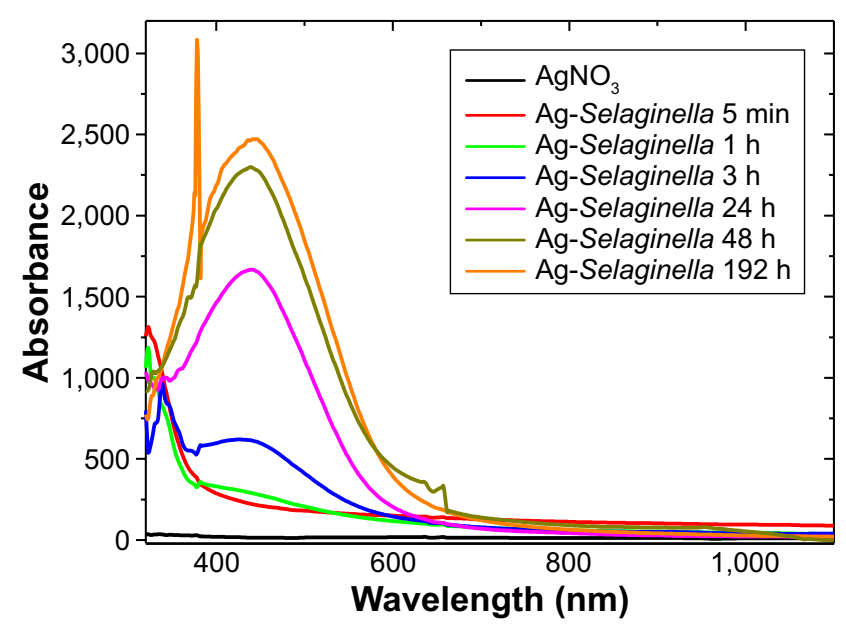

Figure 6 Ultraviolet-visible spectra analysis of synthesized nanoparticles.

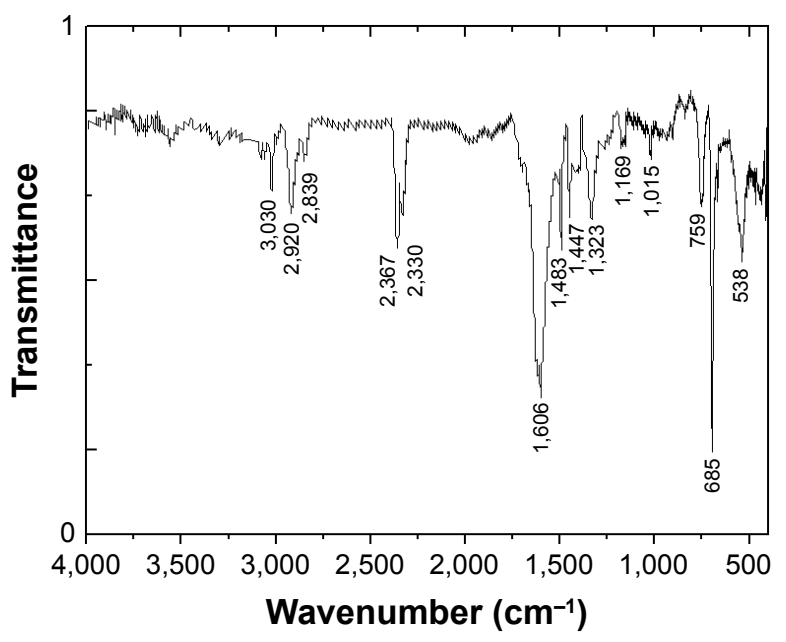

Figure 7 Fourier transform infrared spectrum for synthesized silver nanoparticles using Selaginella myosurus.

illustrates crystalline peaks at $2 \theta$ values of $38^{\circ}, 44.2^{\circ}$, $64.4^{\circ}$, and $77.4^{\circ}$ that can be indexed to the $(111,200$, 220), and (311) planes of the face-centered cubic (fcc) structure, respectively (JCPDS file: 65-2871). The PXRD pattern also showed the presence of the cubic phase of silver chloride at $2 \theta$ values of $27.8^{\circ}, 32.2^{\circ}, 46.2^{\circ}, 54.8^{\circ}$, $57.4^{\circ}, 67.4^{\circ}, 74.4^{\circ}$, and $76.7^{\circ}$ corresponding to the $(111$, $200,220,311,222,400,331)$ and (420) planes, respectively (JCPDS file: 31-1238). The calculated average crystalline particle size was found to be 33.7 and $44.2 \mathrm{~nm}$ for silver and silver chloride, respectively, using the Debye-Scherrer; Equation 3:

$$
D v=\frac{K \lambda}{\beta \cos \theta}
$$

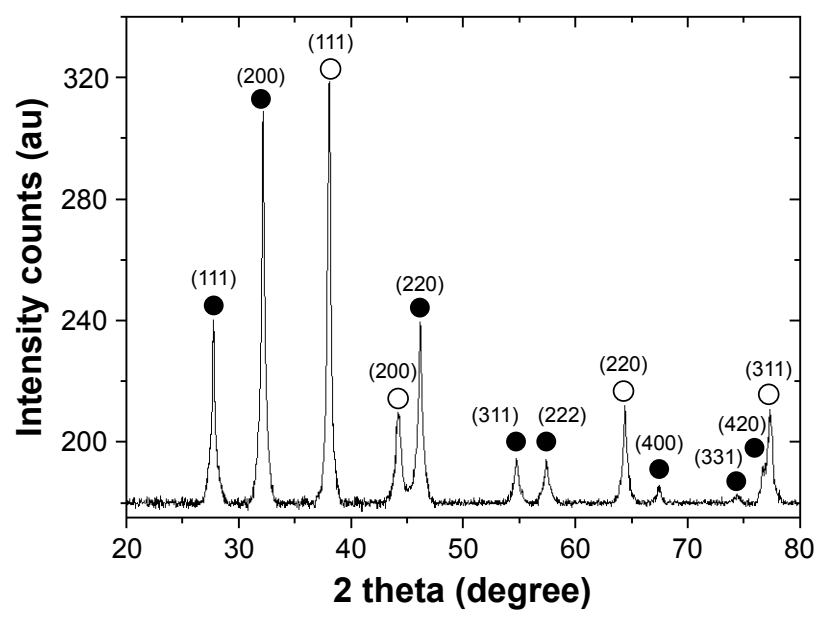

Figure 8 X-ray diffraction pattern of the nanoparticles from Selaginella myosurus; - represents silver nanocrystallites and $\bullet$ represents silver chloride nanocrystallites. 
where $D v$ is the average crystalline size; $K$ is a dimensionless shape factor, with a value close to unity $(0.99) ; \lambda$ is the wavelength of $\mathrm{Cu} \mathrm{K} \alpha ; \beta$ is the full width at half-maximum of the diffraction peaks, and $\theta$ is Bragg's angle.

\section{HR-SEM and EDS results}

Figure 9 shows the HR-SEM image of the synthesized silver nanoparticles. One can distinguish that almost all the nanoparticles are highly crystalline aggregates of spherical shape with varied size. The elemental analysis of the sample was performed using EDS, and the EDS spectrum is shown in Figure 9. The peaks observed at $0.18,3.0$ and $0.12,2.71 \mathrm{keV}$ correspond to the binding energies of silver and $\mathrm{Cl}$, respectively. A peak situated at the binding energy of $1.75 \mathrm{keV}$ belonging to Si has been observed. No peaks of other impurities have been detected, indicating that the silver nanoparticles sample contain pure silver, with no oxide. Furthermore, the sample contained a high concentration of silver nanoparticles, and the atomic percentage was $65.89 \%$, which is shown in Table 1 .

\section{HR-TEM and SAED results}

HR-TEM image of silver colloidal solution providing information on the morphology and size of the nanoparticles is shown in Figure 10. It exhibits that the particles were predominantly spherical in shape. Following the digitization phase of various images, the nanoparticle size (largest diagonal) distribution using ImageJ software was estimated. Such a diagonal was found to be within the 15-95 nm range. By fitting the histogram data with a Gaussian distribution, the average size was found to peak at $58.81 \mathrm{~nm}$. Onset on Figure 10 shows
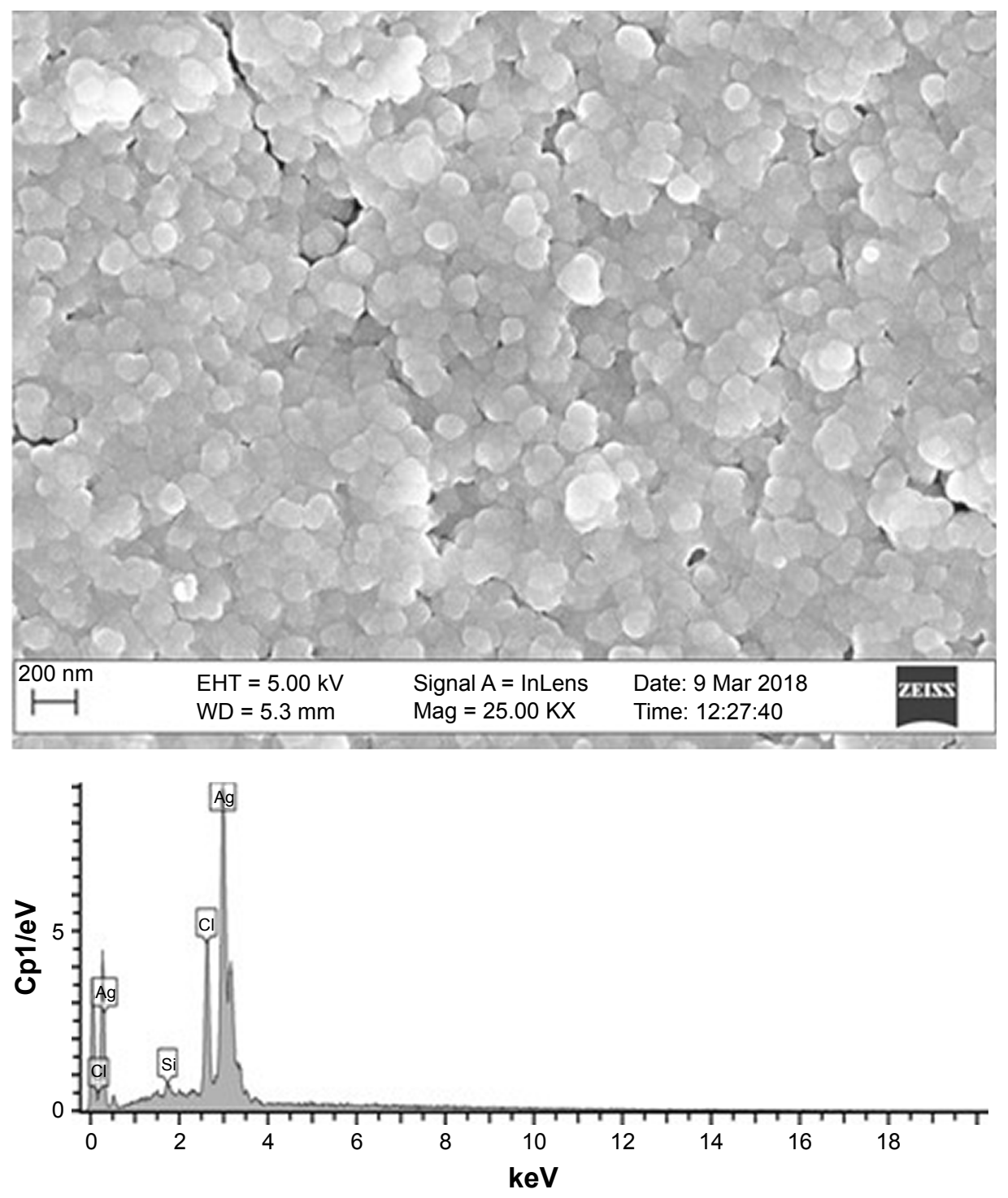

Figure 9 High-resolution scanning electron microscopy image of silver nanoparticles with energy dispersive X-ray spectroscopy profile. 
Table I Energy dispersive X-ray spectroscopy elemental composition of synthesized nanoparticles

\begin{tabular}{|l|l|}
\hline Elements & Atomic \% \\
\hline $\mathrm{Si}$ & 3.41 \\
\hline $\mathrm{Cl}$ & 30.6 \\
\hline $\mathrm{Ag}$ & 65.99 \\
\hline $\mathrm{Total}$ & 100 \\
\hline
\end{tabular}

the SAED pattern of the synthesized silver nanoparticles obtained by directing the electron beam perpendicular to one of the nanoparticles in the aggregate. The patterns of SAED spots were indexed according to reflections of fcc structure of elemental silver and cubic silver chloride, indicating that synthesized silver nanoparticles from $S$. myosurus aqueous extract are crystalline spherical particles. ${ }^{32}$

\section{Inhibition effect of AgNPs on egg albumin denaturation}

The in vitro bioassay results of antiarthritic effect of silver nanoparticles assessed against denaturation of egg albumin are summarized in Table 2 . All tested concentrations significantly $(P<0.001)$ inhibited the denaturation of egg albumin. The maximum inhibition percentage obtained was $99 \%$ at a concentration of $0.2 \mathrm{mg} / \mathrm{mL}$. The acetylsalicylic acid used as a standard drug exhibited an inhibition of $65 \%$ at a concentration of $5 \mathrm{mg} / \mathrm{mL}$.

\section{Effect of AgNPs on carrageenan-induced paw edema in rats}

The effect of silver nanoparticles on carrageenan-induced rat paw edema is shown in Table 3. The injection of carrageenan produced in control animals, a local edema in the following 30 minutes that increased progressively and reaches its peak

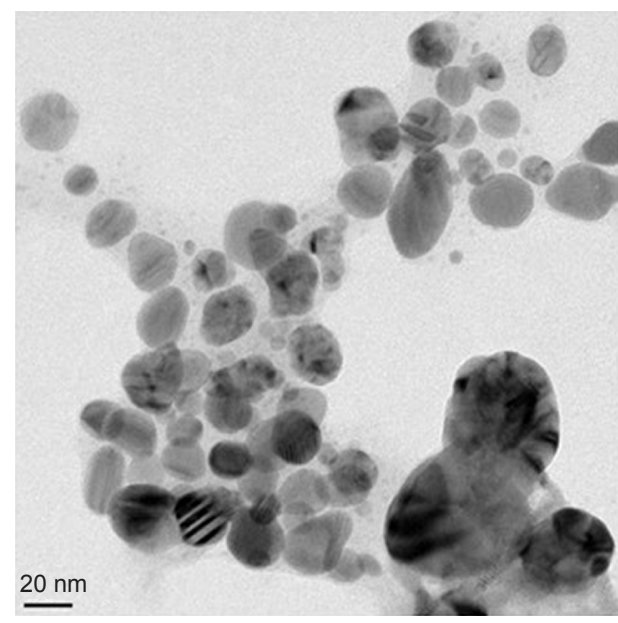

3 hours after carrageenan injection. The oral administration of silver nanoparticles resulted in a significant inhibition of paw edema when compared with control group. The maximum inhibition percentages obtained were $44.30 \%$ ( 1 hour), $57.60 \%$ ( 5 hours), and $60.50 \%$ ( 5 hours) for the doses of 0.1 , 0.2 , and $0.4 \mathrm{mg} / \mathrm{kg}$ (body weight), respectively. Indomethacin used as standard drug showed a significant $(P<0.001)$ protective effect against carrageenan-induced paw edema, by $71.50 \%$ at 5 hours.

\section{Discussion}

The synthesis of silver nanoparticles by green novel and environmental friendly pathway using the natural extract of S. myosurus extract as an effective anti-inflammatory agent was demonstrated. The UV-visible spectra as a function of time illustrated increasing absorbance bands indicating gradual reduction as well as nucleation and growing size of nanoparticles. The absorption spectra of the synthesized silver nanoparticles were recorded against water in order to monitor the formation and stability of silver nanoparticles. The color change of the mixture solution (plant extract and silver nitrate) was first recorded through visual observation. The color change following incubation is due to the formation of plasmon at the colloid surface, indicating the synthesis of silver nanoparticles. ${ }^{33}$ The impact of extract quantity and silver nitrate concentration on the synthesis have been studied. Results show that surface plasmon resonance absorbance band increased with increasing quantities of both reactants. This has been observed for olive leaf extract ${ }^{34}$ or Megaphrynium macrostachyum leaf extract ${ }^{35}$ and optimizes the reaction in producing more nanoparticles. S. myosurus aqueous extract acts as a reductant as well as capping agent, therefore, mediates the synthesis as well as stabilization of

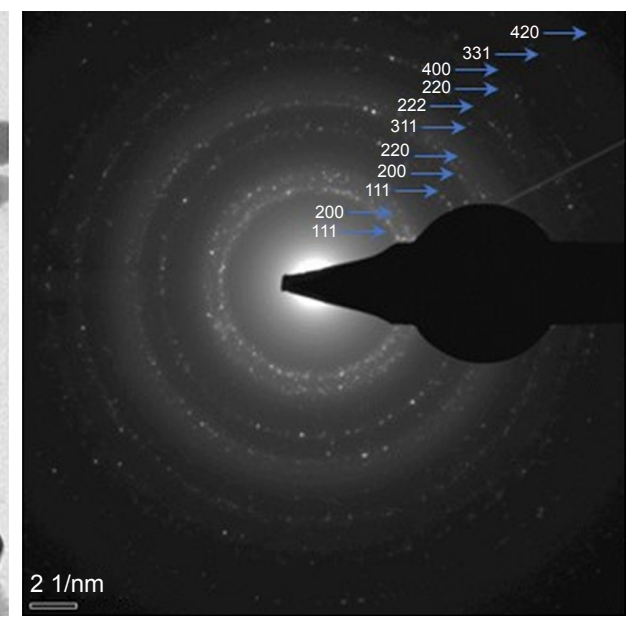

Figure 10 High-resolution transmission electron microscopy image of silver nanoparticles and selected area electron diffraction pattern. 
the silver nanoparticles with characteristic plasmon resonance band in the range $420-480 \mathrm{~nm} .{ }^{33}$ The color intensity of the solution changes from light yellow to deep-brown at the end of the reaction because of increasing amount of silver nanoparticles. It has also been observed that plasmon absorbance bands decreased at lower $\mathrm{pH}$ and increased at higher $\mathrm{pH}$. To our knowledge, such an evolution is not described in the literature. Generally, plasmon absorbance bands increase with increasing $\mathrm{pH}$ from 2 to 12 , such as observed for M. macrostachyum leaf extract-mediated silver nanoparticles. ${ }^{35} \mathrm{~A}$ major influence of the reaction $\mathrm{pH}$ is its ability to change the electrical charges of biomolecules, which might affect their capping and stabilizing abilities and subsequently the growth of the nanoparticles. ${ }^{33}$ Previous studies have shown that the size and shape of biosynthesized nanoparticles could be manipulated by varying the $\mathrm{pH}$ of the reaction mixtures, thereby increasing the rate of the reduction reaction, ${ }^{27,34}$ such as observed for olive leaf extracts and Pinus eldarica bark extract. ${ }^{34,36} \mathrm{pH}$ affects the amount of nanoparticle production and their stability. It is a critical factor to control the size and morphology of nanoparticles. ${ }^{36}$

A typical FTIR spectrum of the obtained silver nanoparticles to identify the potential biomolecules in the plant extract responsible for the reduction and also the capping reagent responsible for the stability of the bioreduced silver nanoparticles was associated with absorption bands, indicating various stretching modes including $\mathrm{C}-\mathrm{H}, \mathrm{N}-\mathrm{H}, \mathrm{O}-\mathrm{H}$, $\mathrm{C}=\mathrm{C}, \mathrm{C}=\mathrm{N}, \mathrm{C}=\mathrm{O}$, and $\mathrm{C}-\mathrm{O} .{ }^{37-39}$ From the FTIR analysis, it is evident that the silver nanoparticles are capped with phytochemicals with various functional groups of organic molecules such as flavonoids, saponins, steroids, terpenoids, tannins, or phenols, which give characteristic peaks in the spectrum. ${ }^{37}$

The typical PXRD pattern of the prepared nanoparticles presented in Figure 5 is compatible with the cubic phase of silver with various diffraction points corresponding to the fcc structure (JCPDS file: 65-2871). The PXRD pattern also showed the presence of the cubic phase of silver chloride (JCPDS file: 31-1238). No other characteristic peaks were found, indicating the high purity of the as-prepared silver and silver chloride nanoparticles. The most intense peaks of silver and silver chloride were chosen to calculate the average crystalline particle size..$^{40}$ Thus, we selected the (111) and (200) lattice planes of silver and silver chloride, respectively. The intense and narrow diffraction peaks revealed the crystalline nature of the synthesized nanoparticles..$^{41}$ Pattern identification shows the formation of pure crystals of silver and silver chloride. Similar observations were made using leaf extracts

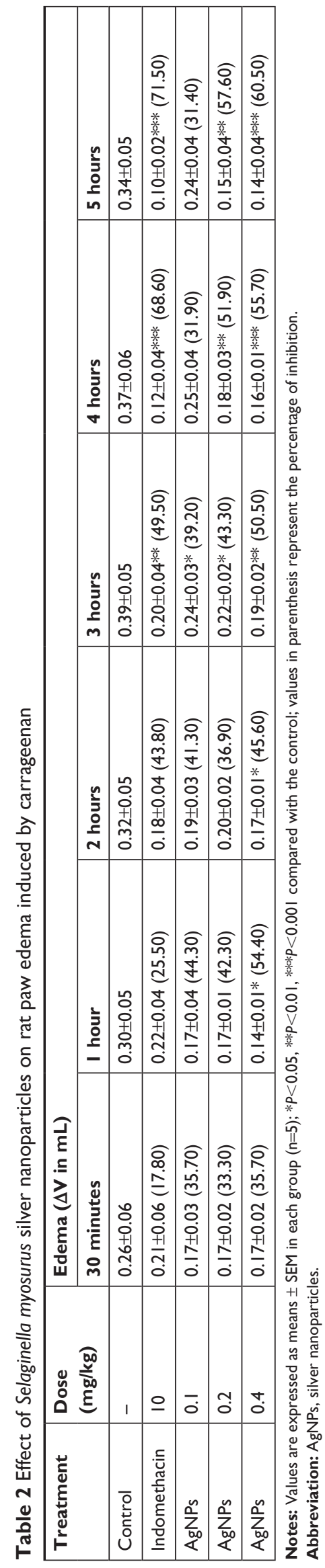


Table 3 Influence of silver nanoparticles and acetylsalicylic acid against protein denaturation

\begin{tabular}{|l|l|l|l|l|}
\hline Sample & Concentration $(\mathbf{m g} / \mathbf{m L})$ & Optical density & $\%$ inhibition & IC $_{50}(\mathbf{m g} / \mathbf{m L})$ \\
\hline Control & - & $2.53 \pm 0.03$ & - & - \\
\hline AgNPs & 0.4 & $0.13 \pm 0.00$ & 94.87 & 0.00073 \\
\hline AgNPs & 0.2 & $0.02 \pm 0.00^{* * *}$ & 98.97 & \\
\hline AgNPs & 0.1 & $0.05 \pm 0.00^{* * *}$ & 97.77 & \\
\hline AgNPs & 0.05 & $0.12 \pm 0.00^{* * *}$ & 95.03 & \\
\hline AgNPs & 0.025 & $0.21 \pm 0.00^{* * *}$ & 91.72 & \\
\hline Acetylsalicylic acid & 100 & $2.22 \pm 0.00$ & 12.42 & \\
\hline Acetylsalicylic acid & 50 & $1.97 \pm 0.27$ & 21.97 & \\
\hline Acetylsalicylic acid & 25 & $1.25 \pm 0.08^{* *}$ & 50.57 & \\
\hline Acetylsalicylic acid & 15 & $1.21 \pm 0.05^{* * *}$ & 52.16 & \\
\hline Acetylsalicylic acid & 10 & $1.08 \pm 0.10^{* * *}$ & 57.20 & \\
\hline Acetylsalicylic acid & 5 & $0.87 \pm 0.06^{* * *}$ & 65.42 & \\
\hline
\end{tabular}

Notes: Values are expressed as means \pm SEM in each group $(n=3) ; * *<<0.01$, *** $>0.001$ compared with the control.

Abbreviations: AgNPs, silver nanoparticles; $I C_{50}$, concentration for $50 \%$ inhibition.

of Corchorus olitorius, Ipomea batatas, or flowers extract of Albizia julibrissin..$^{26,41}$ Distribution, surface morphological, and nanostructural studies of synthesized silver nanoparticles have been investigated using HR-SEM and HR-TEM coupled with EDS and SAED, respectively. It has been found that the synthesized silver nanoparticles were crystalline aggregated, spherical in shape with varied size. Such variation in size is common when using biological systems for the synthesis. ${ }^{42}$ The large polycrystalline nature of the particles may be due to the fact that on the nanometer scale, most of the metals are as fcc structures. They tend to nucleate and grow onto twinned and multiply twinned particles with their surfaces bounded by the lowest energy facets. Silver nanoparticles have the tendency to agglomerate due to their high surface tension of ultrafine nanoparticles. ${ }^{42}$ The fine particle size results in a large surface area that, in turn, enhances the nanoparticle activities. The EDS profile of bioreduced silver ions indicated that the silver nanoparticles contain pure silver without oxide, and SAED pattern clearly confirmed their crystalline nature.

The ability of the synthesized silver nanoparticles to inhibit albumin denaturation has been investigated for potential antiinflammatory action mechanism. It is well documented that protein denaturation is involved in arthritic reactions and development of tissue damage during inflammation. ${ }^{43-46}$ Results reveal that synthesized silver nanoparticles were effective in inhibiting thermally induced albumin denaturation at all tested concentrations, indicating their capability of controlling protein denaturation involved in the inflammatory process. Upon translating from in vitro to in vivo systems, Carrageenan-induced rat hind paw edema model was used to assess the anti-inflammatory potential of silver nanoparticles loaded from S. myosurus aqueous extract. It is a widely used experimental model of acute inflammation that exhibits a high degree of reproducibility. ${ }^{47}$ The characteristic swelling that occurs in the rat paw is due to increased vascular permeability and edema formation. ${ }^{48}$ Edema induced by carrageenan is a triphasic response that involves the release of different mediators including histamine and serotonin in the first phase (1 hour). The second phase is mediated through the release of kinins ( 2 hours), and the third phase is attributed to prostaglandins and cyclooxygenase products, which last from 3 to 5 hours. ${ }^{31,49}$ Oral pretreatment of animals with silver nanoparticles resulted in a significant inhibition $(P<0.001)$ of edema rate during the three phases of inflammation when compared with control group. The maximum inhibition $(60.50 \%)$ was obtained at the dose of $0.4 \mathrm{mg} / \mathrm{kg}$, 5 hours after injection of the phlogistic agent. This result suggests that nanoparticles consisting of silver and silver chloride may interfere with the release of acute inflammatory mediators or antagonize their action. Furthermore, the persistent anti-inflammatory activity might be due to enhanced permeability and retention effect of silver nanoparticles in the edema region that has been reported by Moldovan et al..$^{50}$ Indomethacin, an NSAID used as standard exerted a significant $(P<0.001)$ inhibition of paw edema only at the third phase. Thus, the inhibition of edema formation and albumin denaturation activities of silver nanoparticles from $S$. myosurus aqueous extract clearly establish their anti-inflammatory potential and therefore could be considered as potential source of the antiinflammatory drug. However, one should try to further figure out other action mechanisms responsible for this activity via other detailed experimentations. 


\section{Conclusion}

The concept of nanomedicine has risen to be the future of medicine. Advantages of using silver nanoparticles to treat inflammation have many benefits such as low drug dose efficacy. Silver and silver chloride nanoparticle-mediated $S$. myosurus have been obtained and characterized. Synthetic optimization shows increases in plasmon resonance bands with the solute and extract concentrations as well as $\mathrm{pH}$. The generated particles are found to be crystalline spherical in shape and biofunctionalized with organic molecules. The synthesized silver nanoparticles exhibited significant inhibition of albumin denaturation, indicating a strong anti-inflammatory potential and of edema formation in rats, hence, could be considered as a potential source of the anti-inflammatory drug.

\section{Acknowledgments}

PBEK thanks the African-German Network of Excellence in Science (AGNES) for granting a Mobility Grant in 2017. The Grant is generously sponsored by German Federal Ministry of Education and Research and supported by the Alexander von Humboldt Foundation. The authors are thankful to the Multidisciplinary Laboratory of the Faculty of Medicine and Pharmaceutical Sciences, University of Douala, for technical support.

\section{Disclosure}

The authors report no conflicts of interest in this work.

\section{References}

1. Liao JC, Deng JS, Chiu CS, et al. Chemical compositions, anti-inflammatory, antiproliferative and radical-scavenging activities of Actinidia callosa var. ephippioides. Am J Chin Med. 2012;40(5):1047-1062.

2. Sen S, Chakraborty R, Sridhar C, Reddy YSR, De B. Free radicals, antioxidants, diseases and phytomedicines: current status and future prospect. Int J Pharm Sci Rev Res. 2010;3(1):91-100.

3. Vonkeman HE, Brouwers JR, van de Laar MA. Understanding the NSAID related risk of vascular events. BMJ. 2006;332(7546):895-898.

4. Sajeesh T, Parimelazhagan T. Analgesic, anti-inflammatory, and GC-MS studies on Castanospermum australe A. Cunn. \& C. Fraser ex Hook. Sci World J. 2014;2014:587807.

5. Aparna MKM, Seethalakshmi S, Gopal V. Evaluation of in-vitro antiinflammatory activity of silver nanoparticles synthesised using Piper nigrum extract. J Nanomed Nanotech. 2015;6(2):268-273.

6. da Silva JB, Temponi Vdos S, Gasparetto CM, et al. Vernonia condensate Baker (Asteraceae): a promising source of antioxidants. Oxid Med Cell Longev. 2013;2013:698018.

7. Bonifácio BV, Silva PB, Ramos MA, Negri KM, Bauab TM, Chorilli M. Nanotechnology-based drug delivery systems and herbal medicines: a review. Int J Nanomedicine. 2014;9:1-15.

8. Jiang W, Kim BY, Rutka JT, Chan WC. Advances and challenges of nanotechnology-based drug delivery systems. Expert Opin Drug Deliv. 2007;4(6):621-633.

9. Servat-Medina L, González-Gómez A, Reyes-Ortega F, et al. Chitosantripolyphosphate nanoparticles as Arrabidaea chica standardized extract carrier: synthesis, characterization, biocompatibility, and antiulcerogenic activity. Int J Nanomedicine. 2015;10:3897-3909.
10. Gopinath SM, Niladri SS, Jincy JV, Noor SK, Shyamil G, Ashwini PGM. Biological synthesis, characterization and application of silver nanoparticles - a review. Int J Pharm App. 2013;4(1):19-28.

11. Harekrishna B, Dipak KB, Gobinda PS, Priyanka S, Santanu P, Ajay M. Green synthesis of silver nanoparticles using seed extract of Jatropha curcas. Colloid Surface A Physicochem Eng Aspect. 2009;348(1-3): 212-216.

12. Mansour GM, Robabeh HD, Mostafa K, Mansoureh R, Kamyar S. Green synthesis of silver nanoparticles using plant extracts. Korean J Chem Eng. 2014;31(4):548-557.

13. Galdiero S, Falanga A, Vitiello M, Cantisani M, Marra V, Galdiero M. Silver nanoparticles as potential antiviral agents. Molecules. 2011; 16(10):8894-8918.

14. Eya'ane Meva F, Okalla Ebongue C, Fannang SV, et al. Natural substances for the synthesis of silver nanoparticles against Escherichia coli: the case of Megaphrynium macrostachyum (Marantaceae), Corchorus olitorus (Tiliaceae), Ricinodendron heudelotii (Euphorbiaceae), Gnetum bucholzianum (Gnetaceae), and Ipomoea batatas (Convolvulaceae). J Nanomater. 2017;2017:6834726.

15. Weng JK, Noel JP. Chemodiversity in Selaginella: a reference system for parallel and convergent metabolic evolution in terrestrial plants. Front Plant Sci. 2013;4:119-136.

16. Little DP, Moran RC, Brenner ED, Stevenson DW. Nuclear genome size in Selaginella. Genome. 2007;50(4):351-356.

17. Peters DE, Omeodu SI, Okwara NO. Effect of aqueous whole plant extract of Selaginella myosurus on kidney markers in albinos rats. AASCIT J Biosci. 2015;1(5):93-102.

18. Omeodu SI, Peters DE, Erameh JA. Effect of aqueous whole plant extract of Selaginella myosurus on lipid profile of carbon tetrachloride $\left(\mathrm{CCl}_{4}\right)$-induced hepatotoxicity in Wistar rats. AASCIT J Biosci. 2016;1(5):103-110.

19. Setyawan AD. Review: natural products from Genus Selaginella (Selaginellaceae). Bioscience. 2011;3:44-58.

20. de Sá PG, Nunes XP, de Lima JT, et al. Antinociceptive effect of ethanolic extract of Selaginella convoluta in mice. BMC Complement Altern Med. 2012;12:187.

21. Han BH, Chi HJ, Han YN, Ryu KS. Screening on the anti-inflammatory activity of crude drugs. Korean J Pharmacognosy. 1972;4:205-209.

22. Meng ZM, Saki Y, Ose Y. Antimutagenic activity by the medicinal plants in traditional Chinese medicines. In: Zhu YP, editor. Chinese Materia Medica. Chemistry, Pharmacology and Applications. Boca Raton: CRC Press LLC; 1998:225-229.

23. Almeida JR, Sá P, Alves Ribeiro de Oliveira Macedo L, Siqueira Filho J, Ribeiro de Oliveira V, Barbosa Filho J. Phytochemistry of the genus Selaginella (Selaginellaceae). Journal of Medicinal Plants Research. 2013;7(25):1858-1868.

24. Ono K, Nakane H, Meng ZM, Ose Y, Sakai Y, Mizuno M. Differential inhibitory effects of various herb extracts on the activities of reverse transcriptase and various deoxyribonucleic acid (DNA) polymerases. Chem Pharm Bull (Tokyo). 1989;37(7):1810-1812.

25. Belle EKP, Nguemfo EL, Magne FAL, et al. Acute and chronic antiinflammatory and antioxidant activities of aqueous extract of Selaginella myosurus (Selaginellaceae). In: Proceeding of the 22nd Annual Conference of Cameroon Bioscience Society; December 1-3, 2015; Yaounde, Cameroon, Book of Abstracts, 263.

26. Eya'ane MF, Marcelle LS, Okalla EC, et al. Unexplored vegetal green synthesis of silver nanoparticles: a preliminary study with Corchorus olitorus Linn and Ipomea batatas (L.) Lam. Afr J Biotech. 2016;15(10): 341-349.

27. Eya'ane MF, Seugnou ML, Okalla EC, Vandi D, Ngo Nyobe JC, Mpondo MEA. Synthesis, optimization and effect of condition reactions studies of seed kernel aqueous extract mediated silver nanoparticles from Ricinodendron heudelotii (Baill) Pierre Pax. Int J Biotech. 2015; 7(4):47-56.

28. Dey $\mathrm{P}$, Chatterjee $\mathrm{P}$, Chandra S, Bhattacharya S. Comparative in vitro evaluation of anti-inflammatory effects of aerial parts and roots from Mikania scandens. J Adv Pharm Technol Res. 2011;1:271-277. 
29. Chandra S, Chatterjee P, Dey P, Bhattacharya S. Evaluation of antiinflammatory effect of ashwagandha: a preliminary study in vitro. Pharmacognosy J. 2012;4(29):47-49.

30. Winter CA, Risley EA, Nuss GW. Carrageenin-induced edema in hind paw of the rat as an assay for antiiflammatory drugs. Proc Soc Exp Biol Med. 1962;111:544-547.

31. Lanhers MC, Fleurentin J, Dorfman P, Mortier F, Pelt JM. Analgesic, antipyretic and anti-inflammatory properties of Euphorbia hirta. Planta Med. 1991;57(3):225-231.

32. Elshawy OE, Helmy EA, Rashed LA. Preparation, characterization and in vitro evaluation of the antitumor activity of the biologically synthesized silver nanoparticles. Adv Nanoparticles. 2016;5(2):149-166.

33. Mulvaney P. Surface plasmon spectroscopy of nanosized metal particles. Langmuir. 1996;12(3):788-800.

34. Khalil MMH, Ismail EH, El-Baghdady KZ, Mohamed D. Green synthesis of silver nanoparticles using olive leaf extract and its antibacterial activity. Arabian J Chem. 2014;7(6):1131-1139.

35. Eya'ane MF, Segnou ML, Okalla EC, et al. Spectroscopic synthetic optimizations monitoring of silver nanoparticles formation from Megaphrynium macrostachyum leaf extract. Rev Bras Farm. 2016;26(5): 640-646.

36. Iravani S, Zolfaghari B. Green synthesis of silver nanoparticles using Pinus eldarica bark extract. Biomed Res Int. 2013;2013:639725.

37. Jyoti K, Baunthiyal M, Singh A. Characterization of silver nanoparticles synthesized using Urtica dioica Linn. leaves and their synergistic effects with antibiotics. J Radiat Res Appl Sci. 2016;9(3):217-227.

38. Taraschewski M, Cammenga HK, Tuckermann R, Bauerecker S. FTIR study of $\mathrm{CO}_{2}$ and $\mathrm{H}_{2} \mathrm{O} / \mathrm{CO}_{2}$ nanoparticles and their temporal evolution at $80 \mathrm{~K}$. J Phys Chem. 2005;109(15):3337-3343.

39. Gayathri S, Ghosh OSN, Sathishkumar S. Investigation of physicochemical properties of $\mathrm{Ag}$ doped $\mathrm{ZnO}$ nanoparticles prepared by chemical route. Appl Sci Lett. 2015;1(1):8-13.

40. Wang P, Huang B, Lou Z, et al. Synthesis of highly efficient Ag@AgCl plasmonic photocatalysts with various structures. Chemistry. 2010; 16(2):538-544.
41. Awwad AM, Salem NM, Ibrahim QM, Abdeen AO. Phytochemical fabrication and characterization of silver/silver chloride nanoparticles using Albizia julibrissin flowers extract. Adv Matter Lett. 2015;6(8): 726-730.

42. Annamalai J, Nallamuthu T. Green synthesis of silver nanoparticles: characterization and determination of antibacterial potency. Appl Nanosci. 2006;6:259-265.

43. Opie EL. On the relation of necrosis and inflammation to denaturation of proteins. J Exp Med. 1962;115:597-608.

44. Umapathy E, Ndebia EJ, Meeme A, et al. An experimental evaluation of Albuca setosa aqueous extract on membrane stabilization, protein denaturation and white blood cell migration during acute inflammation. J Med Plants Res. 2010;4:789-795.

45. King AE, Critchley HO, Kelly RW. Presence of secretory leukocyte protease inhibitor in human endometrium and first trimester decidua suggests an antibacterial protective role. Mol Hum Reprod. 2000; 6(2):191-196.

46. Miike S, McWilliam AS, Kita H. Trypsin induces activation and inflammatory mediator release from human eosinophils through proteaseactivated receptor-2. J Immunol. 2001;167(11):6615-6622.

47. Patel MK, Mandavia DR, Patel TK, Barvaliya MJ, Tripathi CB. Evaluation of anti-inflammatory, analgesic, and antipyretic effects of ethanolic extract of Pedalium murex Linn. fruits. Afr J Tradit Complement Altern Med. 2013;10(4):94-100.

48. Di Rosa M, Giroud JP, Willoughby DA. Studies on the mediators of the acute inflammatory response induced in rats in different sites by carrageenan and turpentine. J Pathol. 1971;104(1):15-29.

49. Vinegar R, Truax JF, Selph JL, Johnston PR, Venable AL, McKenzie KK. Pathway to carrageenan-induced inflammation in the hind limb of the rat. Fed Proc. 1987;46(1):118-126.

50. Moldovan B, David L, Achim M, Clichici S, Filip GA. A green approach to phytomediated synthesis of silver nanoparticles using Sambucus nigra L. fruits extract and their antioxidant activity. J Mol Liq . 2016;221:271-278.
International Journal of Nanomedicine

\section{Publish your work in this journal}

The International Journal of Nanomedicine is an international, peerreviewed journal focusing on the application of nanotechnology in diagnostics, therapeutics, and drug delivery systems throughout the biomedical field. This journal is indexed on PubMed Central, MedLine, CAS, SciSearch $®$, Current Contents ${ }^{\circledR} /$ Clinical Medicine,

\section{Dovepress}

Journal Citation Reports/Science Edition, EMBase, Scopus and the Elsevier Bibliographic databases. The manuscript management system is completely online and includes a very quick and fair peer-review system, which is all easy to use. Visit http://www.dovepress.com/ testimonials.php to read real quotes from published authors. 